\title{
LA POSESIÓN EN VIRTUD DE UN TÍTULO MANIFIESTAMENTE NULO ¿DEBE SER CONSIDERADA COMO POSESIÓN PRECARIA?
}

\author{
Claudia Marlenee Mejía Jara ${ }^{1}$
}

\begin{abstract}
RESUMEN
La posesión precaria regulada por el artículo $911^{\circ}$ del código civil señala que es ocupante precario el que no cuenta con un título o cuyo título ha fenecido; mas esta redacción no es del todo adecuada pues omitió el considerar aquel supuesto en el cual la posesión se ejerce en virtud de un título manifiestamente nulo; pues, si bien es cierto que en este caso el poseedor cuenta con un título, este se encuentra viciado, de tal forma que es invalido, pues, en primer término la nulidad supone la ineficacia automática y originaria del negocio jurídico, y esta al ser manifiesta puede ser declarada de oficio por cualquier juzgador que conozca la causa en ejercicio de sus potestades y con la finalidad de tutelar el orden público.
\end{abstract}

\section{ABSTRACT}

The precarious possession regulated by article $911^{\circ}$ of the civil code indicates that the precarious occupant is the one that does not have a title or whose title has expired; but this wording is not entirely adequate because he omitted to consider that assumption in which possession is exercised by virtue of a manifestly null title; then, although it is true that in this case the owner has a title, it is flawed, so it is invalid, then, in the first case, the nullity supposes the automatic and original inefficiency of the legal business, and this being manifest may be declared ex officio by any judge who knows the cause in the exercise of its powers and for the purpose of protecting public order.

\section{PALABRAS CLAVE}

Invalidez del negocio jurídico. Ineficacia del negocio jurídico. Negocio jurídico nulo. Negocio jurídico manifiestamente nulo. Posesión. Posesión precaria.

\section{KEY WORDS}

Invalidity of the legal business. Inefficacy of the legal business. Null legal business. Legal business manifestly null. Possession. Precarious possession.

\section{I.INTRODUCCIÓN:}

En el Perú, tanto los códigos civiles de 1852 y de 1936 no brindaban una definición de la figura jurídica del ocupante precario, es así que, cuando el legislador del código de 1984 redactó el artículo $911^{\circ}$ definiendo al poseedor precario como aquel que posee un bien inmueble sin título alguno o que teniendo un título, este ha fenecido, no previó la gran cantidad de dificultades que la aplicación de este artículo acarrearía, problemas tales como ¿qué sucedería si es que el poseedor del inmueble tuviera un título que adoleciera de una nulidad manifiesta? ¿Califica ser considerado como ocupante precario? 0 acaso ¿debería ser considerado como poseedor ilegítimo mientras no se declare la nulidad del título?
El Cuarto Pleno Casatorio, que tuvo como tema principal de discusión a la posesión precaria señaló que el juez: “(...) declarará fundada o infundada la demanda de desalojo por ocupación precaria dependiendo de cuál de los títulos presentados por las partes para sustentar su derecho, a ejercer la posesión inmediata, es el que adolece de nulidad manifiesta (...)"2 ;

1 Abogado en la Superintendencia Nacional de Administración Tributaria; egresado de la MAESTRÍA EN DERECHO PENAL por la Universidad Antenor Orrego; MAESTRÍA EN DERECHO DE LA EMPRESA por la PUCP. 
esto implica que al momento de evaluar una causa, el juez puede declarar la procedencia del desalojo por precariedad si el poseedor ejerce la posesión únicamente en virtud de un título que adolece de alguna causal de invalidez absoluta y evidente; ahora en virtud a lo señalado por la Corte Suprema, en el presente trabajo procuraremos determinar si es que esta vinculación lógica entre la posesión en virtud de un título manifiestamente nulo y el desalojo por precariedad existe, o si es que no corresponde ser calificado como poseedor precario.

Para dar respuesta a estas interrogantes nos será necesario previamente definir algunos conceptos sobre nulidad, invalidez e ineficacia del negocio jurídico, para luego de esto centrarnos en el tema medular que motivó el presente artículo, que es el determinar si la posesión ejercida con un título afecto de un vicio de nulidad manifiesto puede ser declarado como posesión precaria y explicar el porqué de esta consideración.

\section{II.LA INEFICACIA DEL NEGO- CIO JURÍDICO:}

Aníbal Torres define al acto jurídico ineficaz como aquel acto que "no produce sus efectos normales (todos o alguno de ellos) es calificado de ineficaz. El acto ineficaz tanto cuando no se dan los efectos (sociales, económicos, etc.) perseguidos como cuando se hace cesar, o los efectos no pueden hacerse valer frente a ciertas personas" ${ }^{3}$.

Taboada Cordova señala que: "Un negocio jurídico ineficaz se da cuando los negocios jurídicos no producen nunca efectos jurídicos o dejan de producir efectos jurídicos que han venido produciendo. En estos casos nos encontramos frente a supuestos de ineficacia negocial. De esta manera puede señalarse que los negocios ineficaces son aquellos que nunca han producido efectos jurídicos, o aquellos que habiéndolos producido dejan de producirlos posteriormente por la aparición de una causal sobreviniente a la celebración del mismo negocio" ${ }^{4}$.
Se podría decir que son ineficaces los negocios jurídicos a los que la ley les priva de efectos a modo de sanción por ser incompatibles con el ordenamiento legal, y es que, si bien estos actos pueden operar en el plano de la realidad social, no llegan a hacerlo en la dimensión jurídica, porque les faltan de manera definitiva o solo transitoria alguna circunstancia o requisito constitutivo que el ordenamiento juzga necesarios para que el negocio pueda producir los efectos jurídicos que las partes buscaron alcanzar al constituir el mismo. ${ }^{5}$

Existen dos tipos de ineficacia: la ineficacia originaria y la ineficacia sobreviniente o funcional; la primera de ellas, también es conocida como ineficacia por causa intrínseca estructural, debido a que la causal de ineficacia se presenta en el momento de nacimiento o formación del negocio jurídico ${ }^{6}$, esto la diferencia de la ineficacia funcional, que es una ineficacia sobreviniente a la celebración del negocio jurídico pues un acto jurídico que venía produciendo normalmente sus efectos jurídicos

Cuarto Pleno Casatorio Civil, 2195-2011-Ucayali (Corte Suprema de Lima 13 de agosto de 2012). Pág. 32.

Torres Vásquez, A. (2001). Acto jurídico. Lima: Idemsa. Pág 661. En este mismo sentido Luis Claveria Gonsalez (1977) señala que: "la ineficacia en sentido lato es sencillamente el hecho de que el negocio no produzca los efectos que las partes pretendan, y que, en circunstancias normales, provoca el tipo de negocio de que se trate; o, que ellos estén llamados a decaer en un momento posterior" (pág 23)

4 Taboada Cordova, L. (2002). Acto Jurídico, Negocio Jurídico y Contrato (Primera Edición ed.). Lima: Editorial Jurídica Grijley. Pág. 298

5 Francisco Moreyra García Sayán señala que: “cuando el interés individual expresado en el acto de autorregulación en que consiste el acto jurídico resulta incompatible con el ordenamiento legal. Ello quiere decir que los efectos que los agentes del negocio en concreto quieren alcanzar, si bien pueden operar en el plano de la realidad social, no llegan a hacerlo en la dimensión jurídica de la expresada realidad. En la distinción entre la ineficacia y la invalidez, aquella representa el concepto amplio y esta, el restringido" Garcia Sayon, F. (2005). El acto jurídico según el código civil peruano - curso teórico, histórico y comparativo (Primera edición ed.). Lima: Fondo Editorial de la Pontificia Universidad Católica del Perú. Pág. 319

6 Cuando hacemos mención al momento de celebración o formación del negocio jurídico, nos estamos refiriendo al momento en el cual se conforma o compone el negocio jurídico por la concurrencia de todos los aspectos de su estructura, bien se trate de sus elementos, presupuestos y requisitos. 
deja de producirlos, por eso es también denominada ineficacia por causa extrínseca. ${ }^{7}$

Para los fines que perseguimos en el presente estudio, hemos de ocuparnos principalmente de la ineficacia estructural, misma que como señalamos en el párrafo precedente, se presenta desde el momento mismo de formación del negocio jurídico, siendo este el primer rasgo característico de esta ineficacia; mas, no basta que la causal de ineficacia se produzca al momento de formación del negocio jurídico sino que además de ello es necesario que la referida causal suponga un defecto en la estructura misma del negocio jurídico, es decir, que se trate de un negocio mal formado, con un defecto congénito e intrínseco, un negocio mal estructurado. A este tipo de ineficacia se le conoce como "invalidez" en la doctrina y en los distintos sistemas jurídicos, uno de esos sistemas jurídicos es el nuestro, que en el Código Civil denomina tanto a la nulidad como a la anulabilidad con el nombre genérico de invalidez.

\section{LA INVALIDEZ DEL NEGO- CIO JURÍDICO}

Ahora, para definir la invalidez de los negocios jurídicos podríamos citar lo señalado por Nieto Blanc, quien refiere que: "un acto jurídico esta afectado de inavalidez cuando ni puede generar consecuencias jurídicas, porque sus elementos esenciales se encuentran viciados o faltan. Habrá invalidez cuando un acto jurídico desde su origen y contenido vulnera los límites de lo que está normado. "el concepto de invalidez es el reverso del de validez. Ser válido significa etimológicamente "tener valor, valer" y la noción de valor a la que se extiende la valoración -presupone un elemento de confrontación, es decir un metro o un modelo o tipo como término de misa. Decir pues que el acto es válido significa sostener que corresponde a un deteminado modelo normativo, o sea que es un acto perfecto" ${ }^{8}$.

Así como existe una ineficacia funcional y una ineficacia estructural, también existe una sub clasificación para la invalidez estructral o negocial, es así que la invalidez estructural puede ser absoluta o relativa; es absoluta cuando el presupuesto no cumplido que originó el defecto en la formación no es susceptible de "disposición" por las partes ya sea por que comprometen principios básicos del ordenamiento jurídico o porque comprometen intereses colectivos 0 de terceros; en cambio, se dice que la invalidez estructural es relativa cuando los presupuestos o requisitos incumplidos tiene el carácter de "disponibles" por las partes. Es así que, conforme a lo señalado la invalidez absoluta supone la nulidad del negocio jurídico, en cambio, la invalidez relati- va supone la anulabilidad del referido negocio. En este mismo sentido, doctrinarios como Eugene Petit señala que: "la invalidez tiene modos o maneras de manifestarse. En unos casos estamos frente a la nulidad absoluta o insubsanable en la que no es posible restaurar su validez considerándose como si el negocio no hubiera existido, o por el contrario, la declaración de voluntad existe y por lo tanto el acto jurídico también existe, pero en la voluntad hay un vicio formativo por el que puede ser anulado el acto. En el primer supuesto estamos frente a la inexistencia del negocio o nulidad absoluta. En cambio, en el segundo supuesto existe la anulabilidad o nulidad relativa" ${ }^{9}$.

\section{EL NEGOCIO JURÍDICO NULO}

Como al presente trabajo interesa básicamente lo referente a la nulidad absoluta o insubsanable, hemos de iniciar definiendo al negocio jurídico nulo, mismo que la doctrina nacional califica como: "aquel que carece de algún elemento, presupuesto o requisito, o aquel que teniendo los aspectos de su estructura tiene un contenido ilícito, por contravenir las buenas costumbres, el orden público o normas imperativas"10. En este mismo sentido el profesor italiano Emilio Betti sostiene que "es nulo el negocio jurídico que, por falta de algún elemento

7 Como señala Taboada Córdova (2002): “Los supuestos típicos de ineficacia funcional son la resolución y la rescisión. Sin embargo, debe señalarse que en los casos de la rescisión la causal es coetanea a la celebración del negocio jurídico, a pesar que se trata de un supuesto de ineficacia funcional" (Pág. 298)

8 Nieto Blanc, E. (1971). Nulidad en los Actos Jurídicos. Buenos Aires: El Gráfico. Pág. 27

9 Petit, E. (1961). Tratado de derecho romano. México: Editorial Nacional. Pág. 213

10 Taboada Cordova, L. (2002). Acto Jurídico, Negocio Jurídico y Contrato (Primera Edición ed.). Lima: Editorial Jurídica Grijley. Pág. 300 
esencial, es inapto para dar vida a aquella nueva situación jurídica que el Derecho apareja al tipo legal respectivo, en conformidad con la función económica y económica-social que le es característica". ${ }^{11}$

Podemos afirmar que el negocio jurídico nulo es aquel al cual la ley le aplica su máxima sanción civil, pues a manera de un nacido muerto, la norma le priva completamente de efectos como si no se hubiera realizado jamás, esto por adolecer de algún requisito o presupuesto que esta considera esencial para su conformación, por haberse dictado en violación a las prescripciones ordenadas por ellas; mas, no puede decirse que un acto jurídico nulo es un acto jurídico inexistente, puesto que no puede anularse lo que nunca existió $^{12}$. En este mismo sentido lodrogo Delgado señala respecto a los actos jurídicos nulos y los actos inexistentes que: "un acto jurídico es nulo cuando no puede producir los efectos jurídicos deseados por las partes, por faltarle algún requisito esencial que señala la ley privándole de su eficacia. La nulidad de un acto jurídico supone la existencia, porque no puede anularse lo que no existe. Allí radica la diferencia con un acto inexistente, además que la nulidad de un acto es mas extensa, porque los actos inexistentes son muy excepcionales y se encuentran subsumidos en la teoría de la nulidad". ${ }^{13}$

La nulidad es la sanción civil más grave que consiste privar de efectos jurídicos al negocio inadecuadamente conformado, al ser estos efectos atentatorios contra los intereses que el ordenamiento jurídico protege, y es que, las normas que regulan las nulidades del negocio jurídico tienen carácter sustantivo que no permite que las partes se sustraigan a su cumplimiento, por tal razón, se le da la nominación de normas de orden público que no admiten pacto en contrario, y cuyo incumplimiento genera que el Estado actúe privándole completamente de efectos legales a modo de sanción; Lohmann Luca de Tena señala que "la nulidad es una sanción legal destinada a privar de sus efectos jurídicos propios y queridos a los negocios incursos en una de las causales legalmente establecidas". ${ }^{14}$

Respecto a la declaración de nulidad de los negocios jurídicos Albaladejo sostiene que el acto jurídico nulo, "carece inicial y perpetuamente de todo efecto negocial; permaneciendo la situación jurídica como estaba antes del negocio -acto- jurídico, de tal modo que los interesados - cualquiera pueden seguir comportándose, a tenor de ello, como si aquel no existie- ra (...) la acción y fallos que declaran la nulidad en este caso son meramente declarativas, pues la situación jurídica que existía antes del fallo, continúa con posterioridad a él, lo que se ha producido es una simple formalización de la situación pre-existente (...) siendo que la declaración de nulidad puede $y$ debe incluso efectuarse de oficio, cuando el Juez conoce de los hechos que la provoca"15. (De aquí en adelante el resaltado es nuestro)

La nulidad puede ser expresa o tácita, o bien, textual o virtual; la primera de ellas supone que el legislador la señala expresamente, la segun$\mathrm{da}$, en cambio, deriva lógicamente de la ley, cuando surge una colisión entre una norma de carácter imperativo - cuyo fundamento yace en el orden público- y el negocio jurídico conformado. Vidal Ramírez señala que "la doctrina ha juzgado peligrosamente la admisión de las nulidades virtuales. Sin embargo, la misma doctrina reputa que ellas no implican que opere automáticamente, sino que los órganos jurisdiccionales tengan la facultad de declararlas con el sustento de la norma imperativa contravenida por la autonomía privada. Por lo general, las nulidades virtuales están integradas a las normas prohibitivas en los que no se advierte la sanción de nulidad"16.

11 Betti, E. (2000). Teoria general del negocio jurídico. Genova: Comares S.L. Pág. 410

12 El italiano autor Barbero (1967) sostiene que "el negocio "nulo", a manera de un nacido muerto, es como si jamás hubiese sido realizado: en calidad de "negocio jurídico" bien se lo puede calificar de inexistente; inexistencia y nulidad son perfectamente sinónimos; a la verdadera nulidad se le denomina también inexistencia. Barbero, D. (1967). Sistema del derecho privado. (D. S. Melendo, Trad.) Buenos Aires: Eiea. Pág. 633

13 Lodrogo Delgado, T. (2004). Teoría del acto jurídico. Lima: Segunda edición. Pág 258

14 Lohmann Luca de Tena, G. (1994). El negocio jurídico. Lima: Grijley. Pág 525

15 Albadejo, M. (1993). El negocio jurídico (11ava Edicion ed.). Barcelona: Librería Bosch. Pág. 412

16 Vidal Ramirez, F. (2005). El acto jurídico. Lima: Gaceta Jurídica. Pág 496 
El Estado, como ente rector tiene la obligación de resguardar el orden jurídico y la paz social, es por eso que, ante circunstancias que pongan en peligro este orden, es él el llamado a actuar como ente rector y protector de estos intereses superiores; es en base a esta función, irrogada al Estado, que el legislador a otorgado la facultad al Poder Judicial (como parte de la estructura estatal) de declarar nulo los actos jurídicos cuando la invalidez de estos resulte manifiesta, esta facultad se ve reconocida en el artículo $220^{\circ}$ del Código Civil, mismo que prescribe: "La nulidad a que se refiere el artículo 219 (...) puede ser declarada de oficio por el juez cuando resulte manifiesta. No puede subsanarse por la confirmación". En este mismo sentido, Romero Montez señala que "el interés basado en el orden público justifica una intervención de oficio por parte del Juez competente. Esto quiere decir que si el magistrado que conoce de una litis y constata la existencia de una causal de nulidad absoluta puede, aunque las partes no la invoquen, declara la misma sobre el acto jurídico vinculado a la controversia sin otro requisito que la nulidad sea manifiesta" ${ }^{17}$.

Ahora, el problema radica en que entender por una nulidad manifiesta, pues la definion adecuada de esta nos ayudara a comprender si es que es suficiente la existencia de la misma para que el juzgador pueda ordenar el desalojo por ocupación precaria de un determinado bien inmueble; es así que, podríamos citar lo señaldo por Vidal Ramirez respecto a el termino "manifiesta" utilizado por el artículo $220^{\circ}$ del Código Civil: "el hecho que la nulidad que "resulte manifiesta" se puede orientar a dos significados. El primero, en su significado semantico, la nulidad que "resulta manifiesta" es la que se presenta al descubierto, de manera clara y patente, y frente a la cual el órgano jurisdiccional facilmente se percata de ella y la declara, como cuando se trata de una donación de inmueble en documento privado, siendo así que debe hacerse por escritura pública bajo sanción de nulidad (art 1625) o cuando un testamento oleógrafo se presenta mecanografiado, cuando debe ser totalmente escrito, fechado y firmado por el propio testador (art. 707).

El segundo significado no radica en "lo manifiesto" de la nulidad, sino que se encuentra encubierta pero luego resulta "manifiesta", como cuando se celebra un contrato con una fi- nalidad que no ha sido expresada, pero que es ilícita y en tal caso, si una de las partes recurre al órgano jurisdicional para alcanzar la pretención a la que se siente con derecho, el juzgador podrá evitar la finalidad del contrato y declararlo nulo, aun cuando su invalidez no sea precisamente, la materia de la controversia". ${ }^{18}$

Señala Lohmann que la nulidad manifiesta "puede ser aquello ostensible, patente, que se expresa, muestra, expone, evidencia y revela por y en el acto mismo y que, por tanto, no requiere de prueba extrinseca de su demostración (caso típico, la falta de formalidad legal)"'19. Es decir, una nulidad es manifiesta cuando el vicio que afecta al negocio jurídico aparece de manera muy clara ante el juzgador, de tal forma que a este le es posible declararla de oficio sin necesidad de efectuar mayor indagación al respecto, y sin necesidad de recurrir a otros antecedentes o medios de prueba; es así que, si para determinar la invalidez absoluta del negocio jurídico, el juzgador requiere de otros antecedentes o medios de prueba, entonces el vicio de nulidad no será manifiesto y no podrá ser declarado bajo el tenor del artículo $220^{\circ}$ del Código Civili20; así mismo, debe entenderse por manifies-

17 Romero, F. (2003). Curso del acto jurídico. Lima: Editorial Liberia. Pág. 317

18 Vidal Ramiréz, F. (2005). El acto jurídico. Lima: Gaceta Jurídica. Pág. 500

19 Lohmann Luca de Tena, G. (1992). La nulidad manifiesta. Su declaración judicial de oficio. lus Et Veritas , 50-70. Pág 59

20 Lohmann considera que la nulidad no está de manifiesto y requeire de prueba extrinseca en las siguientes hipotesis:

“i. La de simulación, pues se supone la autenticidad del acto.

ii. La de objeto indeterminado pero cuya determinabilidad no consta del acto, pues se supone la determinabilidad del objeto no que las partes han querido lo impreciso.

iii. La del objeto cuya imposibilidad física sea relativa o singularmente subjetiva, pero no objetiva y absoluta, pues se supone la posibilidad del objeto, no que las partes han querido lo imposible

iv. Y la de finalidad ilícita que no conste del propio acto y que requiere ser comprobada, pues se supone la rectitud como la licitud (como la buena fe) no un proposito del acto que el ordenamiento repudie." Lohmann Luca de Tena, G. (1992). La nulidad manifiesta. Su declaración jurdicial de oficio. lus Et Veritas , 50-70. Pág 60. 
to aquel vicio que se encuentre en el instrumento mismo del acto ineficaz, y no que resulte de la relación que pueda existir entre este instrumento y otros medios de prueba. Romero señala que "la nulidad es manifiesta cuando en el proceso aparece al descubierto de manera muy clara la correspondiente causal y el juez se entera sin haber efectuado ninguna indagación. Es decir, el hecho de ser el juez que conoce la litis lo pone en ese trance. Tal sucede, por ejemplo, cuando descubre que dos personas que dicen ser casados lo son solo por la religión, mas lo han hecho de acuerdo a las formalidades que establece la ley. Lo mismo se puede decir de una litis donde los herederos discuten su derecho a la herencia basados en un testamento, supuestamente ológrafo, pero el juez se percata que dicho instrumento no es ológrafo, es decir de puño y letra del testador, sino que se hizo en máquina de escribir". ${ }^{21}$

La posibilidad que tiene el juzgador de declarar la nulidad manifiesta de oficio, no constituye una potestad dispositiva, sino que muy por el contrario es una obligación del juzgador, quien en cuanto se percate de la existencia de la referida nulidad deberá declararla al ser esta una norma de orden público; ante esto es preciso señalar que, la nulidad manifiesta a que se refiere la norma debe ser una nulidad absoluta (recurrible por cualquier sujeto) y no debe tratarse de una nulidad relativa, pues en estos casos si el juzgador pierde la potestad de declarar la nulidad bajo los preceptos del artículo $220^{\circ}$ del código civil; y que, a su vez, debe tratarse de un defecto estructural gravísimo e insubsanable que le impida al negocio desplegar efectos jurídicos.

Es cierto que como norma general, las sentencias deben de ajustarse a las pretensiones planteadas por las partes, para de esta forma no incurrir en vicios de congruencia; mas, en la aplicación del principio iure not vincuria, en caso existiera una nulidad manifiesta que no hubiera sido alegada por las partes, el juzgador debe pronunciarse sobre esta nulidad, pues en cumplimiento de sus deberes debe velar por el respeto de las normas de orden público. En este mismo sentido afirma Tanataleán Odar (2008) que "si bien la regla general es que las sentencias han de ajustarse a las peticiones de las partes, existe un principio - el iura novit curia- por el cual el juez está en el deber de aplicar el derecho correspondiente al caso aunque no haya sido invocado por las partes o lo haya sido erróneamente. Ergo, en el caso de existir una nulidad irrebatible, no alegada por las partes, el juez tendría que decretarlo de ese modo, sancionando al negocio con nulidad"22.

Esta facultad nulificante que el legislador otorga al juzgador encuentra su principal fundamento en el artículo $\mathrm{V}$ del Título Preliminar del Código Civil, es decir: "el orden público y las buenas costumbres" como limitación de la autonomía de las voluntades; así lo señala la Casación. $N^{\circ}$ 1021-1996 - Huaura: "El acto jurídico es nulo, además de otras causales, cuando es contrario a leyes que interesan al orden público y a las buenas costumbres (...) Que la anotada causal sustantiva de nulidad se fundamenta en la limitación de la autonomía de la voluntad en razón a que los actos jurídicos se celebran contraviniendo normas imperativas que son la expresión del orden público; estas nulidades no operan automáticamente, sino que los jueces tienen la facultad de declararlas con el sustento de la norma imperativa contravenida por la autonomía privada; por lo general, estas nulidades están integradas a las normas prohibitivas provenientes del conjunto del ordenamiento jurídico"23 .

\section{LA POSESIÓN}

Ahora, una vez que se ha sentado los conceptos básicos sobre la invalidez absoluta del acto jurídico y su declaración de oficio, corresponde analizar la figura de la posesión, la posesión ilegitima y finalmente a la posesión precaria.

Se puede definir a la posesión como "el poder de hecho que el hombre ejerce de una manera efectiva $e$ independiente sobre una cosa, con el fin de

21 Romero, F. (2003). Curso del acto jurídico. Lima: Editorial Liberia. Pág 317

22 Tantaleán Odar, R. (2008). La declaración de nulidad manifiesta: ¿Potestad o deber jurídico? Una propuesta interpretativa de la segunda parte del Artículo 220 del Código Civil. Revista de Actualidad Jurídica. Pág 53

23 Casación. N ${ }^{\circ}$ 1021-1996- Huaura. Sala Civil de la Corte Supre $\neg m a$, El Peruano, 11/05/98 
utilizarla económicamente: dicho poder se protege jurídicamente, con prescindencia de saber si corresponde o no a la existencia de un derecho" ${ }^{24}$. La posesión es entendida como el poder de hecho o señorío que ejerce una persona sobre un bien o derecho, sin importar si el poseedor tiene o no animus domini o animus possidendi, la posesión debe existir fácticamente para ser considerada como tal, aquella posesión que únicamente es reconocida por ley, un contrato o judicialmente, pero que no se ejerce de facto no es considerada posesión. En este mismo sentido, Saleilles afirmaba que: "hay potestad de hecho bastante para fundar la posesión, cuando respecto de la cosa disfruta el detentador de iniciativa personal que le confiere un señorío actual, por ilimitado y provisional que sea, con tal que subsista y tenga un carácter de independencia propia, sean cuales fueren el grado y los límites de esta independencia". ${ }^{25}$

La posesión puede ser legítima e ilegítima, la primera de ellas es la que se ejerce conforme a derecho y en concordancia con el ordenamiento jurídico, en cambio la posesión ilegítima es la que se ejerce en contravencion al ordenamiento jurídico, sin tener derecho para poseer el bien.

\section{VI.LA POSESIÓN PRECARIA}

Daniel Ferrer Martin nos dice que existe un doble concepto de precario, "uno restringido, coincidente con el fijado en el Derecho Romano, que considera precario al disfrute gratuito de una cosa ajena, por tolerancia de su dueño, y otro amplio, que ademas del anterior, admite en el precario todos los supuestos de ocupación, tenencia o disfrute de un inmueble sin título, ya porque no se ha tenido nunca, bien por extinción del que se tenía, o con título ineficaz frente al propietario, cuyos casos, a excepción del último, en definitiva, quedan resumidos en el primero, puesto que la ocupación sin título y sin pago de renta equivale al disfrute por tolerancia del dueño"26.

Es así que, en base a lo señalado por Ferrer Martin, podemos afirmar que la figura del ocupante precario o poseedor precario se presenta en tres supuestos distintos, esto es: cuando falta un título que ampare la posesión del bien, por haber fenecido este título ya sea porque el acto jurídico cumplió con su periodo de vigencia, porque varían los efectos de los actos existentes o porque este tíulo es inválido para sustentar la posesión del inmueble.

Jorge E. Castañeda define al poseedor precario como aquel que: "detenta el inmueble o mueble, no como dueño, sino a nombre o en lugar de dueño, la posesión y la posesión precaria son dos situaciónes radicalmente distintas, el poseedor precario nunca será considerado poseedor, por ello mismo, el vicio de la posesión precaria es pertinente y aquel no habrá de usucapir jamás. ${ }^{27}$ " ; y es que, el poseedor precario ejerce un mero poder de hecho sobre la cosa, pues como señala la norma, este poseedor no cuenta con un título que ampare su posesión y por tal este es técnicamente similar al detentador.

Ahora, si es que como hemos señalado en el párrafo precedente, el poseedor precario no cuenta con un título que habilite y justifique su posesión, ya sea porque nunca lo tuvo o porque este feneció, se puede decir que esta posesión es una especie de posesión ilegítima en la cual el poseedor precario no cuenta con título alguno que ampare su posesión. Al respecto algunos autores como Aníbal Vásquez Torres señalan que de conformidad con lo prescrito por el artículo $906^{\circ}$ la posesión ilegítima requiere de un título que adolece de vicios que acarrean su invalidez; en cambio la posesión precaria prescrita por el artículo 911 señala que la posesión precaria es la que es la que se ejerce sin título alguno (nunca existió el título) o cuando el que se tenía ha fenecido. Bajo estos supuestos, una posesión sustentada en un título nulo o anulable (por adolecer de vicios de formo o de fondo) debe ser considerada como posesión ilegítima, incluso si la nulidad es manifiesta, este poseedor debe ser considerado como un poseedor ilegítimo y no como un poseedor precario.

\footnotetext{
2 Vásquez Ríos, A. (2008). Derechos Reales - Los Bienes - La Posesión (Vol. I). Lima: Editorial San Marcos. Pág 295

25 Saleilles. (1927). La posesión de bienes muebles. Madrid: Tecnos. Pág. 335

26 Ferrer Martin, D. (1952). El precario y el juicio de desahucio por causa de precario. Revista de Derecho Privado, XXXVI. Pág 305

27 Castañeda, J. (1973). Los derechos reales. Lima: Villanueva. Pág 335
} 
Sin embargo, en contravención a lo señalado por Vásquez Torres, la doctrina nacional en su mayoría identifica a la posesión precaria como una especie de posesión ilegítima. Avendaño señala que "el poseedor precario es en realidad el poseedor ilegítimo" 28 . Cuadros Villena dice que cuando la norma del art. $911^{\circ}$ "se refiere a la ausencia de título posesorio, se trata de poseedor ilegítimo, del que carece absolutamente de título, quien entró de hecho en la posesión o quien tiene un título nulo o ineficiente para la transmisión posesoria. Este poseedor puede ser de buena fe, si por error o ignorancia de hecho o de derecho desconoce su falta de título, o el vicio que lo invalida o le priva de eficacia" ${ }^{29}$. Sánchez-Palacios, va más allá y sostiene que: "el poseedor ilegítimo será precario, en tanto su título sea nulo o anulable" ${ }^{30}$.

Existe jurisprudencia que señala existe diferencia entre la posesión ilegítima y la posesión precaria, a modo de ejemplo podemos citar a la CASACIÓN $N^{\circ}$ 1521-2002-LIMA, Publica- da en el diario Oficial El Peruano el 01 de junio de 2004, Boletín de Jurisprudencia (Pág. 12143), en dicha ejecutoria queda establecido que “(...) en la posesión ilegítima existe un título pero que adolece de un defecto formal o de fondo y en la posesión precaria no existe título alguno, hecho que conduce a determinar que la posesión ilegítima no puede ser equiparada a la posesión precaria"31.

Somos de la opinión que la distinción planteada entre la posesión ilegítima y la posesión precaria, no es tal, esto debido a que cuando un poseedor no cuenta con un título, posee en virtud de un título fenecido o posee el bien con un título inválido afecto de una nulidad manifiesta (que pueda ser declarada por el juzgador sin necesidad de una instancia probatoria), está ejerciendo una posesión ilegítima, sin documento alguno que sustente a la misma.

La jurisprudencia española, como bien señala Cano Moria- no, consideraba precarios a: "aquella ocupación de un inmueble ajeno sin pago de una renta ni merced y sin título para ello, o cuando el que se invoca es ineficaz frente al poseedor real a título de dueño, usufructario o cualquier otro que le de derecho a disfrutarlo o sea poseedor jurídico" ${ }^{32}$.

Ahora, señalamos que es poseedor precario el que posee en virtud de un título manifiestamente nulo porque, si bien es cierto en este caso el poseedor cuenta con un título, este está viciado de tal forma que es inválido, pues en primer término la nulidad supone la ineficacia automática y originaria del negocio jurídico, y esta al ser manifiesta puede ser declarada de oficio por cualquier juzgador que conozca la causa en ejercicio de sus potestades y con la finalidad de tutelar el orden público; y es que, como hemos señalado precedentemente al abordar el tema de la nulidad del negocio jurídico: "la nulidad supone preliminarmente la ineficacia automática, total y

28 Avendaño Valdez, J. (1985). La posesión en el Código Civil de 1984 , en Libro Homenaje a José León Barandiarán. Lima: Cultural Cuzco S.A. Pág 35

29 Cuadros Villena, C. (1995). Derechos reales. Tomo I. Lima: Editorial Cultural Cuzco S.A. Pág 308

30 Sánchez -Palacios Paiva, M. (2003). El ocupante precario . Lima: Ediciones legales. Pág. 95

31 En este mismo sentido resuelven la CASACIÓN N 2872-2003- UCAYALI: Fecha de Publicación en el diario Oficial El Peruano: 31 de mayo de 2005, Boletín Sentencia de Casación (Pág. 14173). "que, atendiendo a reiterada jurisprudencia y doctrina mayoritaria que sobre el particular existe, en los Procesos sobre desalojo, el demandante deberá acreditar la propiedad del bien que reclama y el demandado que posee el bien en virtud a un título que justifica dicha posesión, que debe precisarse que es poseedor precario, aquel que carece de título que sustente la posesión que viene ejerciendo sobre determinado bien, independientemente si dicho título es uno válido o no". Y la CASACIÓN № 1682-2006-LAMBAYEQUE de fecha 22 de noviembre de 2006, en la cual el demandante recurrente alegó de que la Sala Civil Superior debió declarar de oficio la nulidad de la Cláusula Séptima de la escritura pública de Constitución de una Asociación Civil, pues solo se trata de una declaración unilateral que de ninguna manera constituye título que acredite la propiedad de la demandada. La Sala Civil Transitoria de la Corte Suprema consideró que tratándose de un documento público, aun cuando se afirme que este es un acto unilateral, por haber transferido los demandados un inmueble que no les pertenecía, a una institución creada por ellos, dicho documento mantiene su validez mientras no se declare judicialmente su nulidad, la misma que no puede operar de oficio, como pretende la casante, pues para ello se requiere de una vía más lata en la que se cuente con los elementos de juicio necesarios para establecer la configuración de algún de las causales de nulidad previstas en el artículo 219 del Código Civil, concluyendo que el mejor derecho de propiedad respecto del bien o, en su caso, la validez de la segunda transferencia aludida, debe ser discutido en una vía distinta a la sumarísima, por lo que la demanda de desalojo por precario deviene en improcedente. Entre otras que fallan en el mismo sentido.

32 Cano Moriano, G. (1952). Estudio sobre la figura del precario. Revista de Derecho Privado , XXXVI. Pág 90. 
original del negocio concreto y de los efectos típicos que se encuentra llamado a producir de acuerdo a su tipología legal o social. Esto supone que, si bien el negocio no puede ser privado absolutamente de relevancia jurídica, pues vale siquiera en su calidad de hecho jurídico, es decir como acontecimiento, el derecho trunca sus efectos como negocio tal cual es"33. En este mismo sentido se ha pronunciado la jurisprudencia cuando señala que:

\section{- CASACIÓN No 2009-2002-} JULIACA-PUNO, publicada en el Boletín "Sentencias de Casación" del diario oficial El Peruano, el 31 de enero del 2005, estableció, en un proceso de desalojo por precario, que “...el contrato notarial de anticresis, no se encuentra formalizado por escritura pública, de conformidad con lo que establece el artículo 1005 del CC de 1936, corroborado con el artículo 1092 del CC actual, resultando por tanto nulo por carecer del requisito de forma a que se refiere el inciso tercero del artículo 1123 del CC de 1936, referido a que el acto jurídico es nulo, cuando no reviste la forma prescrita en la ley." La citada ejecutoria suprema concluye en el noveno considerando que "siendo nulo el contrato de anticresis, los demandados resultan ser precarios, de conformidad con el artículo 911 del CC, que establece que la posesión precaria es la que se ejerce sin título alguno o cuando el que se tenía feneció."
- CASACIÓN N 864-2003CONO NORTE: Resolución de fecha 13 de agosto de 2003. "Así mismo, para considerarse precario debe darse la ausencia absoluta de cualquier circunstancia que justifique el uso o disfrute del bien por parte de la emplazada; y el título de la posesión no tiene porque constar en documento de fecha cierta 0 en instrumento público (...) para que se configura la precariedad prevista en el artículo novecientos once del Código Civil deberá tenerse en consideración que el poseedor carezca no solo de título, sino también de la ausencia de cualquier circunstancia por medio de la cual puede advertirse la legitimidad de dicha posesión".

- CASACIÓN N $\mathrm{N}^{\circ}$ 2884-2003 LIMA: publicado en el Diario Oficial El Peruano el 01 de agosto de 2005 en el Boletín Sentencias de Casación (Pág. 14406), señalando que "si la parte demandada ostenta un título que justifique su posesión, ésta no puede calificarse de precaria, ya que lo único que configura la precariedad de la posesión es la carencia absoluta o el fenecimiento de un título, más no la falta de justo título (...) la precariedad en el uso de bienes inmuebles, a que se refiere dicha norma, no se determina únicamente por la carencia de un título de propiedad, arrendamiento u otro semejante; sino que ésta debe ser entendida como la ausencia absoluta de cualquier circunstancia que permita advertir la legitimidad de la posesión que ostenta el ocupante; en esa amplitud de criterio debe interpretarse la norma contenida en el artículo ciento once del Código $\mathrm{Ci}$ vil (debería decir novecientos once)".

- CASACIÓN N N 4149-2007JUNÍN: publicada en El Peruano 03 de enero del 2008 , señala que "la precariedad en el uso de bienes inmuebles, a que se refiere el artículo 911 del Código Civil, no se determinara únicamente por la carencia de un título de propiedad, de arrendamiento u otro semejante; sino que esta debe ser entendida como la ausencia absoluta de cualquier circunstancia que permita advertir la ilegitimidad de la posesión que ostenta el ocupante, de acuerdo con la amplitud de criterio con el que debe interpretarse la norma contenida en el citado artículo 911 del Código Civil."

- CASACIÓN N N 2195-2011UCAYALI (sentencia del Cuarto Pleno Casatorio): "en efecto, la no existencia de un título o el fenecimiento del que se teníacon el cual justificaba su posesión el demandado- se puede establecer como consecuencia de la valoración de las pruebas presentadas, de dicha valoración es que surge en el juez la convicción de la no exis-

33 Palacios, E. (22 de abril de 2002). Nulidad del negocio jurídico. Obtenido de Dike: portal de información y opinión legal de la Pontificia Universidad Católica del Perú. : http://dike.pucp.edu.pe/?civ. Pág. 17. 
tencia de título o que el acto jurídico que lo originó contiene algún vicio que lo invalida, como es una nulidad manifiesta prevista por alguna de las causales del artículo $219^{\circ}$ del Código Civil, o en todo caso, cuando siendo válido el negocio jurídico, este ha dejado de surtir efectos por alguna causal de resolución o rescisión, pero sin que el juez del desalojo se encuentre autorizado para declarar la invalidez, nulidad, ineficacia, etc. de dicho acto jurídico, por cuanto ello corresponde al juez donde se discuta tal situación (...) si en el trámite de un proceso de desalojo, el Juez de la causa, del análisis de los hechos y de la valoración de los medios probatorios aportados por las partes, advierte la invalidez absoluta y evidente del título posesorio, conforme lo prevé el artículo $220^{\circ}$ del Código Civil, solo analizará dicha situación en la parte considerativa de la sentencia, la sentencia, al exponer las razones que justifican su decisión, y declarará fundada o infundada la demanda de desalojo por ocupación precaria, dependiendo de cuál de los títulos presentados por las partes para sustentar su derecho, a ejercer la posesión inmediata, es el que adolece de nulidad manifiesta"

Un acto jurídico nulo adolece de invalidez estructural, es por eso que se le priva de efectos -jurídicamente hablando-, y esto se agrava si es que el vicio salta a la vista, valga decir: "es manifiesto", pues, al ser evidente la invalidez el juzgador debe actuar en resguardo del orden público y las buenas costumbres y declarar la nulidad del acto jurídico de oficio; la doctrina más acreditada y moderna ha puesto de relieve por un lado, que la previsión de la nulidad del negocio constituye el medio para la tutela efectiva de intereses generales considerados valores fundamentales para la entera organización social y por otro, siendo esto una consecuencia de lo anterior, que la nulidad viene proyectada como un "instrumento de control normativo" utilizado, junto a otros, para no dispensar tutela jurídica a aquellos intereses que estén en contraste con los valores fundamentales del sistema; y es que, tal como señala Vega Vega (1998) "la nulidad absoluta puede y debe ser declarada por el juez, aun sin peticion de parte, cuando aparece de manifiesto en el acto, de donde se deduce que el extremo de no haber formado parte de la litis no es óbice para su declaración en cualquier instancia" ${ }^{34}$.

Gonzales Barrón sostiene que: "precario todo poseedor inmediato que recibió el bien en forma temporal por acto voluntario realizado por el concedente o poseedor mediato, cuya finalidad es proporcionar una liberalidad, gracia o benevolencia. Sus notas causales son que el precario carece de título jurídico o que el título obligatorio de restitución ha fenecido por nulidad manifiesta. El precario es un poseedor inmediato, temporal, gratuito y que obtuvo el disfrute por acto de voluntad del poseedor mediato, pero que no constituye un título jurídico. Esta definición tiene la ventaja de hacer compatible los artículos 911, 921 y 923 CC, así como los artículos 585, 586 y 587 $C P C{ }^{\prime 3}$. Aunque este autor tenga como idea la restitución del concepto romano de precario - teoría que considero errada-, hace una importante precisión al señalar que un precario es tal cuando: "el título obligatorio de restitucion ha fenecido por nulidad manifiesta"; esto debido a que, como se señaló en los párrafos precedentes, un título manifiestamente nulo adolece de validez jurídica, no pudiendo ser oponible frente a nadie pues esta invalidez es manifiesta, y debe ser declarado por el juzgador -al ser una cuestión concerniente al mantenimiento del orden público y las buenas costumbres-; así mismo, el cuestionamiento a la posesión en virtud a un título manifiestamente nulo tampoco podría ser dilucidada en un proceso mas lato que el de desalojo por ocupación precaria, puesto que, al adolecer de un vicio manifiesto, el juzgador, en base a lo prescrito por el art. $220^{\circ}$ del Código Civil debe declarar de ofico la nulidad, pues existe un deber legal de declarar esta nulidad y no someter la

34 Vega Vega, J. (1998). El acto jurídico en las instituciones del derecho civil. Lima: Palestra Editores. Pág 307.

35 Gonzales Barrón, G. (17 de mayo de 2011). LA POSESIÓN PRECARIA, EN SÍNTESIS (y réplica contra los positivistas radicales). Pág. 15. Obtenido de gunthergonzalesb.com: http://www.google.com.pe/url?q=http://www.gunthergonzalesb.com/GGB.\%252017.05.2011/articulosjurídicosGGB/ultimos/precarioensintesis.pdf\&sa=U\&ei=av5jVLOBCqLasATijoGoAw\&ved=0CAsQFjAA\&usg=AFQjCNExRMMUmgjh5QKLjCSZZDuCzzz7bw 
controversia a otras vías que lo único que lograrían seria dilatar la litis contraviniéndose de esta forma la economia procesal buscada y la eficiencia que la administración de justicia debe ostentar.

En el supuesto que alguien pretendiera sustentar su posesión en un título manifiestamente nulo se podría decir que, este título carece de validez -si existe en el mundo de los hechos pero no en el mundo del derecho- y que si esta carencia de validez es manifiesta y apreciable a simple vista por el juzgador, este debe declararla de oficio; todo, a fin de resguardar el orden público y las buenas costumbres; y que en aplicación del principio de iure not vincuria que le permite al juez aplicar el derecho aun cuando este no haya sido invocado o haya sido erróneamente invocado; asimismo, es de señalar que esta no es una facultad, sino que mas bien es un deber que tiene el juzgador a pronunciarse sobre la materia.

Asmismo, no podría decirse que la causal de precariedad: "existencia de un título manifiestamente nulo" se encuentra incluido dentro del supuesto jurídico de "no tiene título", debido a que un acto nulo es inválido jurídicamente hablando, inválido para el mundo del derecho, pero si existe en el mundo de los hechos, puede surtir efectos hasta que sea declarado nulo, tal como señala lodrogo Delgado: "un acto jurídico es nulo cuando no puede producir los efectos jurídicos deseados por las partes, por faltarle algún requisito esencial que señala la ley privándole de su eficacia. La nulidad de un acto jurídico supone la existencia, porque no puede anularse lo que no existe. Allí radica la diferencia con un acto inexitente, ademas que la nulidad de un acto es mas extensa, porque los actos inexistentes son muy excepcionales y se encuentran subsumidos en la teoría de la nulidad"36. Cuando se celebra un negocio jurídico, por más que este sea inválido según las normas jurídicas, puede venir siendo ejecutado por las partes y hasta inclusive puede consolidarse siendo imposible declarar su nulidad si es que transcurren más de diez años; entonces, cabría preguntarse ¿Cómo algo que no existe puede surtir efectos y ser imposible de nulificar?, y es que realmente nunca algo inexistente puede surtir efectos, es por eso que se afirma que un negocio jurídico nulo si existe, mas esta existencia está sancionada con la invalidez al carecer de los elementos esenciales para que pueda surtir los efectos deseados por las partes.

Teniendo en consideración lo señalado, podríamos concluir que el incluir el supuesto de "poseer con título manifiestamente nulo" dentro de los supuestos señalados por la norma para calificar una posesión como precaria permitiría evitar perjuicios a los justiciables, quienes ya no se verían obligados a iniciar nuevos procesos en los cuales tengan que discutir la invalidez del título, evitando así, gastos económicos y, permitiendo, además, el ahorro de tiempo, materializándose de esta forma la aplicación del principio de economía procesal, pues, al ser un acto jurídico al cual el ordenamiento jurídico le priva de efectos no debe ser usado para justificar un derecho sobre un bien.

\section{CONCLUSIONES}

1. La nulidad de un negocio jurídico supone preliminarmente la ineficacia automática, total y original del negocio concreto y de los efectos que normalmente está llamado a producir. Cuando la nulidad es manifiesta, puede ser declarada de oficio por el juez que está conociendo la causa, por más que esta no hubiera sido alegada por las partes; entendiéndose por manifiesta aquella nulidad que se aprecia en el instrumento mismo del acto.

2. Un negocio jurídico nulo adolece de invalidez estructural, es por eso que se le priva de efectos -jurídicamente hablando-, y esto se agrava si es que el vicio salta a la vista, valga decir: "es manifiesto", pues, al ser evidente la invalidez el juzgador debe actuar en resguardo del orden público y las buenas costumbres y declarar la nulidad del acto jurídico de oficio.

3. El poseedor precario es aquel que: no cuenta con un título que sustente su posesión, posee en virtud de un título fenecido o posee el

\footnotetext{
36 Idrogo Delgado, T. (2004). Teoría del acto jurídico. Lima: Segunda edición. Pág 258
} 
bien con un título invalido afecto de una nulidad manifiesta (que pueda ser declarada por el juzgador sin necesidad de una instancia probatoria); a su vez se puede decir que este poseedor precario está ejerciendo una posesión ilegítima, sin documento alguno que sustente a la misma.

4. Es poseedor precario el que posee en virtud de un título manifiestamente nulo porque, si bien es cierto en este caso el poseedor cuenta con un título, este se encuentra viciado, de tal forma que este es inválido, pues, en primer término la nulidad supone la ineficacia automática y originaria del negocio jurídico, y esta al ser manifiesta puede ser declarada de oficio por cualquier juzgador que conozca la causa en ejercicio de sus potestades y con la finalidad de tutelar el orden público.

5. Incluir el supuesto de "poseer con título manifiestamente nulo" dentro de la posesión precaria permitiría evitar perjuicios a los justiciables quienes ya no se verían obligados a iniciar nuevos procesos en los cuales tengan que discutir la invalidez del título, evitando así, gastos económicos $y$, permitiendo, además, el ahorro de tiempo, materializándose de esta forma la aplicación del principio de economía procesal, pues, al ser un acto jurídico al cual el ordenamiento jurídico le priva de efectos no debe ser usado para justificar un derecho sobre un bien.

\section{REFERENCIAS BIBLIOGRÁFICAS}

Albadejo, M. (1958). El negocio jurídico. Barcelona: Libreria Bosch.

Albadejo, M. (1993). El negocio jurídico (11ava Edicion ed.). Barcelona: Libreria Bosch.

Álvarez Caperochipi, J. (1986). Curso de derechos reales: propiedad y posesión. Madrid: $\mathrm{Ci}$ vitas.

Ariano, E. (2003). Sobre el poder del juez de "declarar" de oficio la nulidad ex art. 220 CC en Problemas del Código Civil. Lima: Jurista Editores.

Avendaño, J. (1990). Derechos Reales. Materiales de enseñanza para el estudio del libro V del Código Civil en la Facultad de Derecho (Segunda edición ed.). Lima: Fondo Editorial de la Pontificia Universidad Católica del Perú.

Avendaño Valdez, J. (1985). La posesión en el Código Civil de 1984 , en Libro Homenaje a José León Barandiarán. Lima: Cultural Cuzco S.A.

Barbero, D. (1967). Sistema del derecho privado. (D. S. Melendo, Trad.) Buenos Aires: Eiea.

Betti, E. (2000). Teoría general del negocio jurídico. Genova: Comares S.L.

Bravo, D. C. (1985). El negocio jurídico. Madrid: Editorial Civitas.

Cano, G. (1999). Estudio sobre la figura del precario. Madrid: Edersa.
Cano Moriano, G. (1952). Estudio sobre la figura del precario. Revista de Derecho Privado, XXXVI.

Castañeda, J. (1973). Los derechos reales. Lima: Villanueva.

Claveria Gosalbez, L. (1977). La confirmación del contrato anulable. Bolonia: Publicaciones del Real Colegio de España.

Cuadros Villena, C. (1995). Derechos reales. Tomo $I$. Lima: Editorial Cultural Cuzco S.A.

Cuarto Pleno Casatorio Civil, 2195-2011-Ucayali (Corte Suprema de Lima 13 de agosto de 2012).

Diez-Picazo. (1986). Fundamentos del derecho civil patrimonial (Vol. II). Madrid: Tecnos.

Escobar Rozas, F. (2010). Código Civil Comentado por los Cien Mejores Autores. Tomo I. Lima: Gaceta Jurídica.

Ferrer Martin, D. (1952). El precario y el juicio de desahucio por causa de precario. Revista de Derecho Privado, XXXVI.

García Sayán, F. (2005). El acto jurídico según el código civil peruano - curso teórico, histórico y comparativo (Primera edición ed.). Lima: Fondo Editorial de la Pontificia Universidad Católica del Perú.

Galgano, F. (1992). El negocio jurídico. Valencia: Tirant lo Blanch. 
Gonzales Barrón, G. (17 de mayo de 2011). LA POSESIÓN PRECARIA, EN SÍNTESIS (y réplica contra los positivistas radicales). Obtenido de gunthergonzalesb.com:

http: / / www.google.com. pe/url?q=http ://www. gunthergonzalesb.com / GGB.\%252017.05.2011/articulosjurídicosGGB/ultimos/precarioenstesis. $p d f \& s a=u \& e i=a-$ v5jvlobcqlasatijogoaw\&ved=0casqfjaa\&usg=afqjcnexrmg jh5qklcszzduczzz7bw

Gonzales Barrón, G. (05 de agosto de 2012). Los vaivenes jurisprudenciales sobre el precario. Obtenido de http: / / www. derechoycambiosocial. com/revista022/precario_y_ sus_vaivenes.pdflodrogo Delgado, T. (2004). Teoría del acto jurídico. Lima: Segunda edición.

Jimenéz Vargas-Machuca, R. (Noviembre de 2012). La nulidad del acto jurídico declarada de oficio por el juez. Obtenido de Derecho y Cambio Social: http://www.derechoycambiosocial.com/ revista009/nulidad $\% 20$ de $\% 20$ oficio.htm

Lama More, H. (15 de Septiembre de 2013). "Nulidad de oficio de negocio jurídico". Obtenido de http:// www.rimjc.org/w/index2. php?option=com_content\& do_pdf=1\&id=242

Lama, H. (2006). La posesión y la posesión precaria en el derecho civil peruano. Lima: Fondo Editorial de la Pontificia Universidad Católica del Perú.

León Barandiarán, J. (1991). Tratado de derecho civil pe- ruano (Primera edicion ed., Vols. Tomo II - Acto jurídico). Lima: Walter Rodríguez Editor.

Lohmann Luca de Tena, G. (1994). El negocio jurídico. Lima: Grijley.

Lohmann Luca de Tena, G. (1992). La nulidad manifiesta. Su declaración judicial de oficio. lus Et Veritas , 50-70.

Morales Hervias, R. (25 de 01 de 2010). Las imperfecciones normativas de la nulidad del contrato en el Código Civil. Obtenido de http://moraleshervias.blogspot.com/2007/07/ las-imperfecciones-normativas-de-la-html

Morales Hervias, R. (18 de octubre de 2013). Revista Actualidad Jurídica. Obtenido de http: / / moraleshervias.blogspot.com/2007/07/las-imperficciones-normativas-de-laht$\mathrm{ml}$

Nieto Blanc, E. (1971). Nulidad en los Actos Jurídicos. Buenos Aires: El Gráfico.

Pacheco, T. (1872). Tratado de derecho civil (Vol. III). Lima: Imprenta del Estado.

Palacios, E. (22 de abril de 2002). Nulidad del negocio jurídico. Obtenido de Dike: portal de información y opinión legal de la Pontificia Universidad Católica del Perú. : http://dike.pucp.edu.pe/?civ

Petit, E. (1961). Tratado de derecho romano. México: Editorial Nacional.

Puig Peña, F. (1958). Tratado de derecho civil español. Madrid: Revsita de derecho privado.
Quintana, A., \& Montgomer, W. (2006). Metodología de la Investigación Científica Cualitativa. Lima: Universidad Nacional mayor de San Marcos

Ramírez Cruz, E. (2013). La posesión precaria en la vision del Cuarto pleno casatorio $\mathrm{Ci}$ vil: Doctrina versus jurisprudencia. Gaceta Civil y procesal Civil , 47-59.

Ripert, G. y. (1956). Tratado de derecho civil. Tomo I. Buenos Aires: La Ley.

Romero, F. (2003). Curso del acto jurídico. Lima: Editorial Liberia.

Saleilles. (1927). La posesión de bienes muebles. Madrid: Tecnos.

Sánchez -Palacios Paiva, M. (2003). El ocupante precario. Lima: Ediciones legales.

Taboada Cordova, L. (1992). Acto jurídico. Buenos Aires: Astrea.

Taboada Córdova, L. (2002). Acto Jurídico, Negocio Jurídico y Contrato (Primera Edición ed.). Lima: Editorial Jurídica Grijley.

Tantaleán Odar, R. (2008). La declaración de nulidad manifiesta: ¿Potestad o deber jurídico? Una propuesta interpretativa de la segunda parte del Artículo 220 del Código Civil. Revista de Actualidad Jurídica (174).

Torres Vásquez, A. (2001). Acto jurídico. Lima: Idemsa.

Torres Vásquez, A. (2006). Derechos Reales Tomo I. Lima: Idemsa. 
Torres Vásquez, A. (2008). Derechos reales. La posesión - Los Bienes (Vol. Tomo I). Lima: Editorial San Marcos.

Torres Vásquez, A. (s.f.). www. etorresVásquez.com.pe. Recuperado el 15 de agosto de 2013, de: http://www.etorresVásquez. com.pe/pocesionprecaria.html
Vásquez Ríos, A. (2008). Vidal Ramírez, F. (1998). El acto Derechos Reales - Los Bie- jurídico. Lima: Gaceta Jurídica nes - La Posesión (Vol. I). Editores.

Lima: Editorial San Marcos.

Vega Vega, J. (1998). El acto jurídico en las instituciones del derecho civil. Lima: Palestra Editores.
Vidal Ramírez, F. (2005). El acto jurídico. Lima: Gaceta Jurídica.

Zannoni, E. (2000). Eficacia y nulidad de los actos jurídicos. Buenos Aires: Editorial Astrea . 